\title{
Efficacy and safety of sodium-glucose cotransporter 2 inhibitors initiation in patients with acute heart failure, with and without type 2 diabetes: a systematic review and meta-analysis
}

Husam M. Salah', Subhi J. Al'Aref', Muhammad Shahzeb Khan², Malek Al-Hawwas' ${ }^{1}$, Srikanth Vallurupalli', Jawahar L. Mehta', J. Paul Mounsey', Stephen J. Greene' ${ }^{2,3}$, Darren K. McGuire ${ }^{4}$, Renato D. Lopes ${ }^{2,3}$ and Marat Fudim ${ }^{2,3^{*}}$

\begin{abstract}
Background: There is uncertainty and limited data regarding initiation of sodium-glucose cotransporter 2 (SGLT2) inhibitors among patients hospitalized with acute heart failure (AHF). This systematic review and meta-analysis aim to establish the efficacy and safety of SGLT2 inhibitors initiated in patients hospitalized for AHF.

Methods: PubMed/Medline, Embase, and Cochrane library were searched using the following terms: ("sglt2" and "acute heart failure") and ("sglt2" and "worsening heart failure") from inception till November 15th, 2021 for randomized controlled trials (RCTs) comparing the efficacy and safety of initiating an SGLT2 inhibitor compared with placebo in patients with AHF. Major cardiovascular and diabetes scientific meetings in 2021 were also searched for relevant studies. Prespecified efficacy outcomes were all-cause mortality, rehospitalization for heart failure, and improvement in Kansas City Cardiomyopathy Questionnaire (KCCQ) scale score. Prespecified safety outcomes were acute kidney injury (AKI), hypotension, and hypoglycemia. Random effects odds ratio (OR) and mean difference with 95\% confidence intervals (Cls) were calculated.
\end{abstract}

Results: Three RCTs with a total of 1831 patients were included. Initiation of SGLT2 inhibitors in patients with AHF reduced the risk of rehospitalization for heart failure (OR 0.52; $95 \% \mathrm{Cl}[0.42,0.65])$ and improved Kansas City Cardiomyopathy Questionnaire scores (mean difference 4.12; $95 \% \mathrm{CI}[0.1 .89,6.53]$ ). There was no statistically significant effect for initiation of SGLT2 inhibitors in patients with AHF on all-cause mortality (OR 0.70; $95 \% \mathrm{Cl}[0.46,1.08])$. Initiation of SGLT2 inhibitors in patients with AHF did not increase the acute kidney injury (OR 0.76; $95 \% \mathrm{Cl}[0.50,1.16])$, hypotension (OR 1.17; 95\% Cl [0.80, 1.71]), or hypoglycemia (OR 1.51; 95\% Cl $[0.86,2.65])$.

Conclusion: Initiation of SGLT2 inhibitors in patients hospitalized for AHF during hospitalization or early post-discharge (within 3 days) reduces the risk of rehospitalization for heart failure and improves patient-reported outcomes with no excess risk of adverse effects.

Keywords: Sodium-glucose cotransporter 2 inhibitors, Heart failure, Acute, Initiation, Outcomes, Systematic review, Meta-analysis

\footnotetext{
*Correspondence: marat.fudim@duke.edu

2 Division of Cardiology, Department of Medicine, Duke University, 2301 Erwin Road, Durham, NC, USA
}

Full list of author information is available at the end of the article permits use, sharing, adaptation, distribution and reproduction in any medium or format, as long as you give appropriate credit to the original author(s) and the source, provide a link to the Creative Commons licence, and indicate if changes were made. The images or other third party material in this article are included in the article's Creative Commons licence, unless indicated otherwise in a credit line to the material. If material is not included in the article's Creative Commons licence and your intended use is not permitted by statutory regulation or exceeds the permitted use, you will need to obtain permission directly from the copyright holder. To view a copy of this licence, visit http://creativecommons.org/licenses/by/4.0/. The Creative Commons Public Domain Dedication waiver (http://creativecommons.org/publicdomain/zero/1.0/) applies to the data made available in this article, unless otherwise stated in a credit line to the data. 


\section{Background}

Results from randomized clinical outcomes trials (RCTs) and meta-analyses of patients with heart failure (HF) have shown that sodium-glucose cotransporter 2 (SGLT2) inhibitors improve cardiovascular (CV) outcomes in patients with chronic HF irrespective of diabetes status and across a wide spectrum of left ventricular ejection fraction [1-7]. In a meta-analysis of the EMPEROR-Reduced and DAPA-HF trials, both of which investigated SGLT2 inhibitors in patients with chronic HF with reduced ejection fraction (HFrEF), SGLT2 inhibitors resulted in a $13 \%$ reduction in all-cause death, $14 \%$ reduction in cardiovascular death, $31 \%$ reduction in first hospitalization for HF, and $38 \%$ reduction in adverse renal outcomes in these patients [8]. Given the robust evidence supporting the use of SGLT2 inhibitors in patients with HFrEF, the updated American and European guidelines in 2021 included SGLT2 inhibitors in the guideline-directed medical therapies (GDMT) for chronic HFrEF $[9,10]$. In contrast, data regarding initiation of SGLT2 inhibitors among patients hospitalized with acute HF are more limited, and relative uncertainty regarding safety, tolerability, and efficacy with in-hospital initiation may cause clinicians to defer initiation of SGLT2 inhibitors to the outpatient setting [11]. This underscores the importance of evaluating the efficacy and safety of SGLT2 inhibitor initiation in patients hospitalized for AHF. Herein, the aim of this meta-analysis is to derive more reliable estimate of the efficacy and safety of SGLT2 inhibitors initiated in patients hospitalized for AHF.

\section{Method}

PubMed/Medline, Embase, and Cochrane library from inception until November $15^{\text {th }}, 2021$, were searched using the following terms: ("sglt2" and "acute heart failure") and ("sglt2" and "worsening heart failure"). The major cardiovascular and diabetes meetings in 2021 (American Heart Association [AHA] Scientific Sessions 2021, American College of Cardiology Scientific Sessions 2021, European Society of Cardiology 2021 Congress, American Diabetes Association Scientific Sessions 2021, Heart Failure Society of America Scientific Meeting 2021, European Association for the Study of Diabetes 2021) were searched for relevant unpublished studies. The search was restricted in PubMed/Medline and Embase to clinical trials only using their advanced search tool. No other restrictions (e.g., sample size, follow-up period, or language) were applied. The prespecified selection criteria were: (1) randomized placebo-controlled clinical trials (RCTs); (2) the active arm of the trial included an SGLT2 inhibitor that was initiated in patients hospitalized with AHF; (3) trials reported selected prespecified efficacy and safety outcomes. Prespecified efficacy outcomes were all-cause mortality, rehospitalization for heart failure, and improvement in Kansas City Cardiomyopathy Questionnaire (KCCQ) scale score [12, 13]. Prespecified safety outcomes were acute kidney injury (AKI), hypotension, and hypoglycemia. The efficacy outcomes were chosen based on prior studies showing reduction in the risk of all-cause mortality and hospitalization for HF and improvement in KCCQ scale score in patients receiving SGLT2 inhibitors outside of the context of AHF [5, 14]. Safety outcomes were chosen based on tolerability concerns related to AKI, hypotension, and hypoglycemia in the setting of initiation of SGLT2 inhibitors in AHF [11].

Two investigators (H.M.S. and M.F.) conducted the study search, selection, and data abstracting. The same investigators independently appraised the potential risks of bias using the Cochrane Risk of Bias Tool 2.0 [15] and assessed the quality of the evidence using the GRADE (Grading of Recommendations Assessment, Development and Evaluation) approach (GRADEpro GDT) (https://gdt.gradepro.org/app/handbook/handbook. html\#h.svwngs6pm0f2).

A random effects model meta-analysis was conducted using Mantel-Haenszel odds ratios (ORs) and the associated 95\% confidence intervals (CIs) to assess all-cause mortality, rehospitalization for HF, worsening HF, AKI, hypotension, and hypoglycemia, and the inverse variance of weighted mean difference and associated 95\% CIs were used to assess changes in KCCQ. The Cochrane $\mathrm{Q}$ statistic, and Higgins and Thompsons' $\mathrm{I}^{2}$ were used to evaluate heterogeneity, and the GRADE (Grading of Recommendations Assessment, Development and Evaluation) approach to assess the certainty of the evidence was used. Heterogeneity was considered to be low if $\mathrm{I}^{2}$ is less than $25 \%$, moderate if $\mathrm{I}^{2}$ is between 25 and $75 \%$, and high if $\mathrm{I}^{2}$ is greater than $75 \%$. Assessment for publication bias was limited due to the low number of studies $(<10)$ each with limited statistical power. A sensitivity analysis was done by excluding the results of the unpublished EMPULSE trial. All analyses were done using the Review Manager software (version 5.4.1, The Cochrane Collaboration, 2020).

\section{Results}

The initial search yielded 106 studies (94 from databases and 12 from scientific meetings). After applying the inclusion criteria, only 3 trials with a total of 1831 patients were included (two from databases and 1 from the AHA Scientific Sessions 2021; Fig. 1) [3, 16]. Follow-up periods differed between the included studies (60 days in the EMPA-RESPONSE-AHF, 90 days in the EMPULSE trial, and a median of 9 months in the SOLOIST-WHF trial). Characteristics of the included 


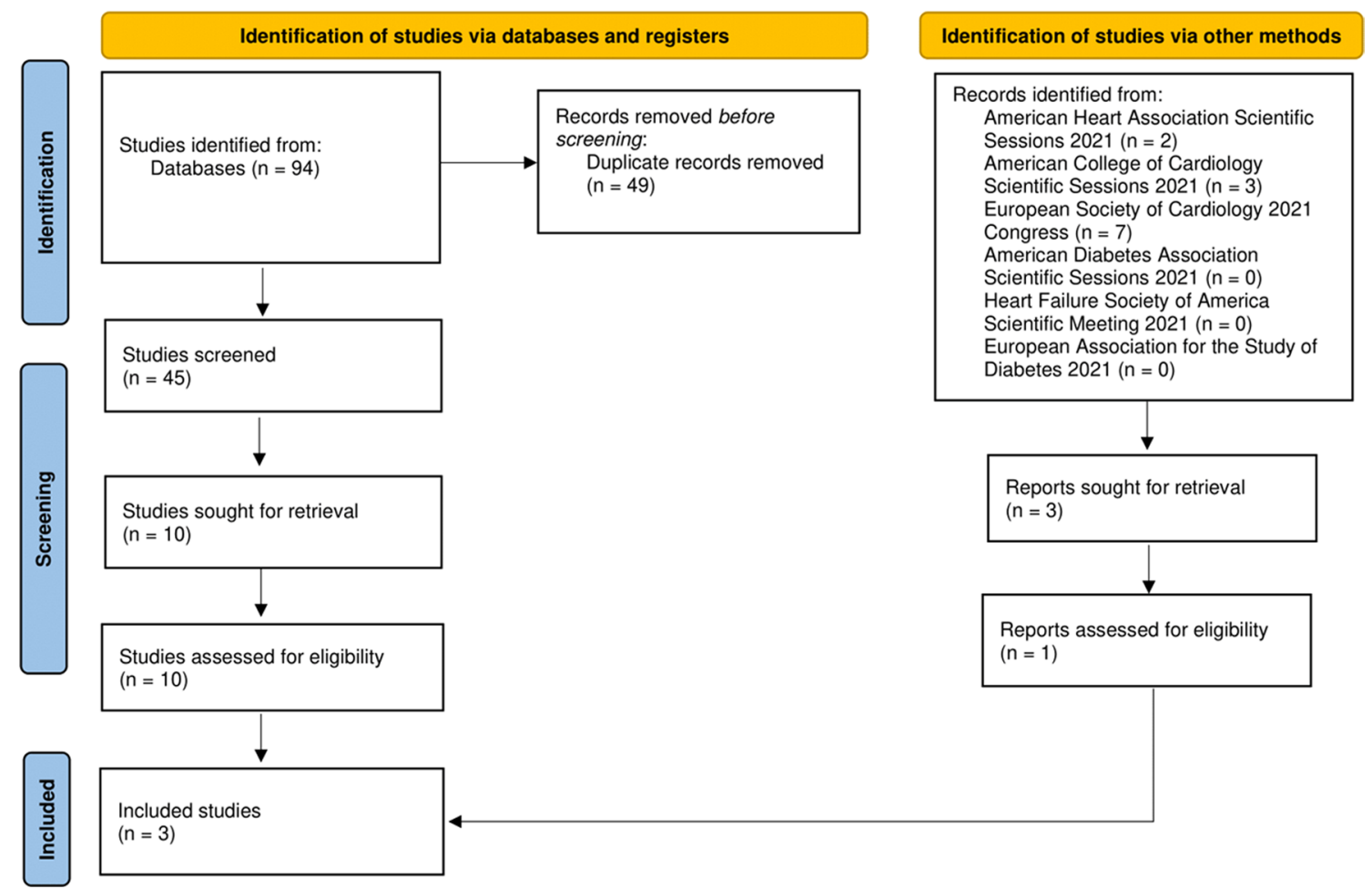

Fig. 1 Preferred Reporting Items for Systematic Reviews and Meta-Analyses (PRISMA) flow diagram for the included studies

studies are summarized in Table 1. All studies were considered to have a low risk of bias (Fig. 2). Due to the lack of power with less than 10 studies included, we did not seek to evaluate for publication bias using the funnel plot approach [17]. Certainty of evidence assessment is summarized in Additional file 1: Table S1. Risk of bias and certainty of evidence for the unpublished EMPULSE trial were assessed based on the published study design and the AHA Scientific Sessions 2021 presentation [18].

Initiation of SGLT2 inhibitors in patients with AHF reduced the risk of rehospitalization for HF (OR 0.52 ; $95 \%$ CI $[0.42,0.65] ; \mathrm{I}^{2}=0 \%$; certainty: high) and improved KCCQ scores, which were measured 4 months after treatment in the SOLOIST-WHF trial and 90 days after treatment in the EMPUSLE trial (mean difference 4.12; 95\% CI [0.1.89, 6.53]; $\mathrm{I}^{2}=0 \%$; certainty: high; Fig. 3).

There was no statistically significant effect for initiation of SGLT2 inhibitors in patients with AHF on all-cause mortality (OR 0.70 ; 95\% CI $[0.46,1.08]$; $\mathrm{I}^{2}=18 \%$; certainty: high). Initiation of SGLT2 inhibitors in patients with AHF did not increase the risk AKI (OR 0.76; 95\% CI $[0.50,1.16] ; I^{2}=10 \%$; certainty: high), hypotension (OR 1.17; 95\% CI [0.80, 1.71]; $\mathrm{I}^{2}=0 \%$; certainty: high), or hypoglycemia (OR 1.51 ; 95\% CI $[0.86,2.65]$; $\mathrm{I}^{2}=0 \%$; certainty: high; Fig. 4). Sensitivity analysis by excluding the unpublished EMPULSE trial from the analysis yielded consistent results (Fig. 5).

\section{Discussion}

The main findings of this systematic review and metaanalysis are that initiation of SGLT2 inhibitors in patients with AHF during hospitalization or early post-discharge carries $48 \%$ lower odds of rehospitalization for $\mathrm{HF}$ and significant improvements in patient-reported outcomes (as measured by KCCQ), without excess risk of AKI, hypotension, or hypoglycemia.

Previous studies have shown that failure to initiate GDMT at discharge from a HF hospitalization is associated with a considerable risk that this therapy will not be started during subsequent follow-ups or will be started with significant delay $[19,20]$. In contrast, patient discharged on GDMT are more likely to be adherent with these therapies following their discharge [20]. Hesitation to start SGLT2 inhibitors in patients hospitalized with AHF stems from concerns of adverse effects in these patients with a clinically tenuous status (e.g., hypotension, AKI, and hypoglycemia) [11]. The present metaanalysis demonstrates that initiating GDMT with SGLT2 inhibitor in patients with AHF during their hospitalizations or shortly thereafter (within 3 days of discharge) is safe and significantly reduces the risk of rehospitalization 
Table 1 Characteristics of the included studies

\begin{tabular}{|c|c|c|c|}
\hline Trial & EMPA-RESPONSE-AHF & SOLOIST-WHF & EMPULSE trial \\
\hline Year & 2020 & 2021 & 2021 \\
\hline SGLT2 inhibitor agent & Empagliflozin & Sotagliflozin & Empagliflozin \\
\hline Type of patients & $\begin{array}{l}\text { Patients with acute heart failure regard- } \\
\text { less of diabetes status }\end{array}$ & $\begin{array}{l}\text { Patients with acute heart failure and type } \\
2 \text { diabetes }\end{array}$ & $\begin{array}{l}\text { Patients with acute heart failure } \\
\text { regardless of diabetes status }\end{array}$ \\
\hline Participants (N) & 79 & 1,222 & 530 \\
\hline SGLT2 inhibitor group (N) & 40 & 608 & 265 \\
\hline Placebo group (N) & 39 & 614 & 265 \\
\hline Age, years (mean) & 76 & 69 & 71 \\
\hline Women (\%) & $33 \%$ & $34 \%$ & $33 \%$ \\
\hline Race & $\begin{array}{l}\text { Empagliflozin group had 100\% Whites, } \\
\text { whereas placebo group had } 95 \% \text { Whites } \\
\text { and } 5 \% \text { others }\end{array}$ & $\begin{array}{l}\text { Sotagliflozin group had } 93.3 \% \text { Whites, } \\
4.1 \% \text { Blacks, and } 1.3 \% \text { Asians, whereas } \\
\text { placebo group had } 93.2 \% \text { Whites, } 4.1 \% \\
\text { Blacks, and } 1.1 \% \text { Asians }\end{array}$ & $\begin{array}{l}\text { Not reported in the American Heart } \\
\text { Association } 2021 \text { presentation }\end{array}$ \\
\hline Diabetes & $\begin{array}{l}\text { Empagliflozin group: } 38 \% \\
\text { Placebo group: } 28 \%\end{array}$ & $100 \%$ in both groups & $\begin{array}{l}\text { Empagliflozin group: } 46.8 \% \\
\text { Placebo group: } 43.8 \%\end{array}$ \\
\hline Hypertension & $\begin{array}{l}\text { Empagliflozin group: } 68 \% \\
\text { Placebo group: } 56 \%\end{array}$ & Not reported & $\begin{array}{l}\text { Empagliflozin group: } 77.4 \% \\
\text { Placebo group: } 83.4 \%\end{array}$ \\
\hline Myocardial infarction & $\begin{array}{l}\text { Empagliflozin group: } 30 \% \\
\text { Placebo group: } 38 \%\end{array}$ & Not reported & $\begin{array}{l}\text { Empagliflozin group: } 24.9 \% \\
\text { Placebo group: } 23.4 \%\end{array}$ \\
\hline Beta-blocker use & $\begin{array}{l}\text { Empagliflozin group: } 70 \% \\
\text { Placebo group: } 66 \%\end{array}$ & $\begin{array}{l}\text { Sotagliflozin group: } 92.8 \% \\
\text { Placebo group: } 91.4 \%\end{array}$ & Not reported in the AHA presentation \\
\hline ACEi use & $\begin{array}{l}\text { Empagliflozin group: } 40 \% \\
\text { Placebo group: } 47 \%\end{array}$ & $\begin{array}{l}\text { Sotagliflozin group: } 41.8 \% \\
\text { Placebo group: } 39.3 \%\end{array}$ & Not reported in the AHA presentation \\
\hline ARB use & $\begin{array}{l}\text { Empagliflozin group: } 5 \% \\
\text { Placebo group: } 3 \%\end{array}$ & $\begin{array}{l}\text { Sotagliflozin group: } 40.3 \% \\
\text { Placebo group: } 44 \%\end{array}$ & Not reported in the AHA presentation \\
\hline ARNI use & $\begin{array}{l}\text { Empagliflozin group: } 5 \% \\
\text { Placebo group: } 3 \%\end{array}$ & $\begin{array}{l}\text { Sotagliflozin group: } 15.3 \% \\
\text { Placebo group: } 18.2 \%\end{array}$ & Not reported in the AHA presentation \\
\hline MRA use & $\begin{array}{l}\text { Empagliflozin group: } 48 \% \\
\text { Placebo group: } 45 \%\end{array}$ & $\begin{array}{l}\text { Sotagliflozin group: } 66.3 \% \\
\text { Placebo group: } 62.7 \%\end{array}$ & Not reported in the AHA presentation \\
\hline Follow-up & 60 days & 9 months & 90 days \\
\hline
\end{tabular}

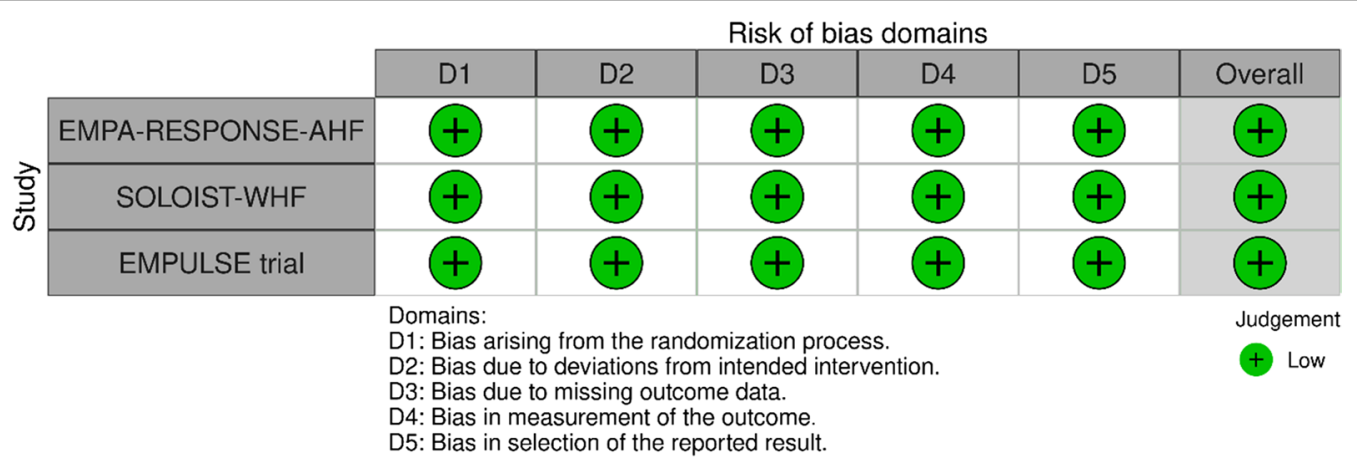

Fig. 2 Risk of bias assessment using the Risk of Bias 2.0 tool. As the EMPUSLE trial results are not published yet, its risk of bias assessment was done based on its published design and the publicly available American Heart Association 2021 presentation

following discharge. These findings, in the light of the previous studies $[19,20]$, suggest that failure to initiate SGLT2 inhibitors in patients with AHF would be a significant missed opportunity that would prevent rehospitalization, improve quality of life, and jeopardize the opportunity to address the rising trend of hospitalization for $\mathrm{HF}$ in the recent years [21,22].

In addition to the mechanisms driving the chronic cardioprotective benefits of SGLT2 inhibitors (e.g., optimizing cardiac energy metabolism, anti-inflammatory 


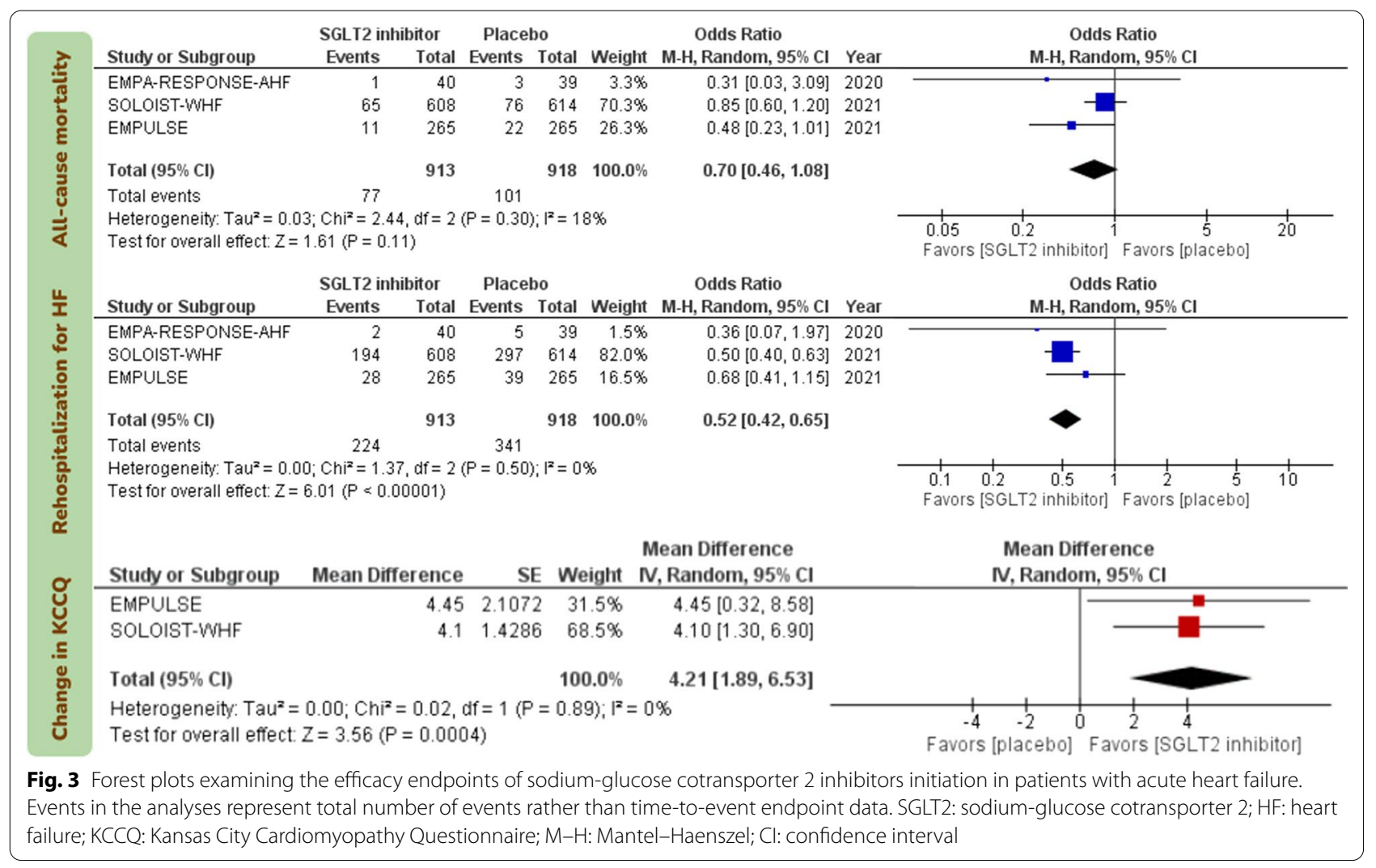

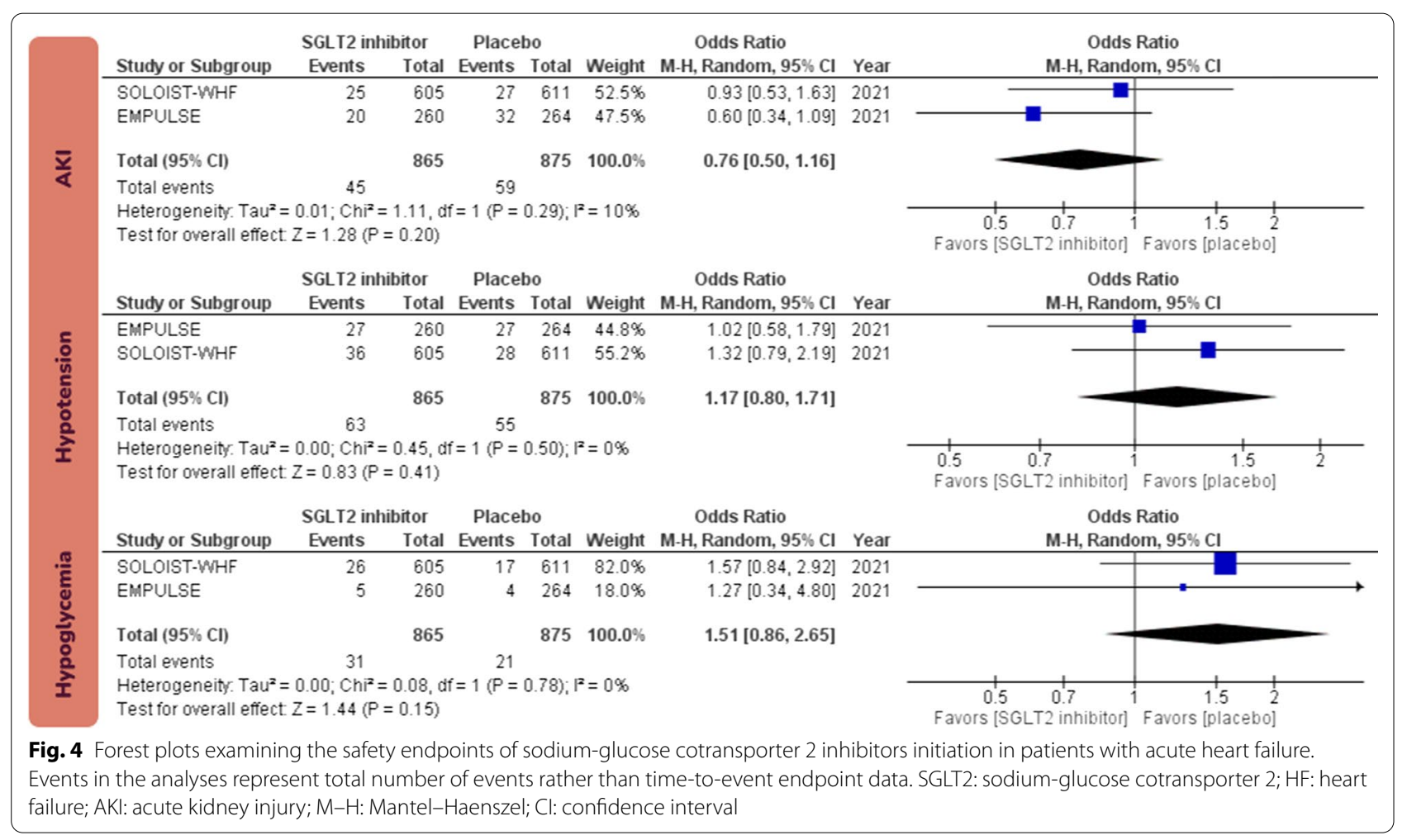




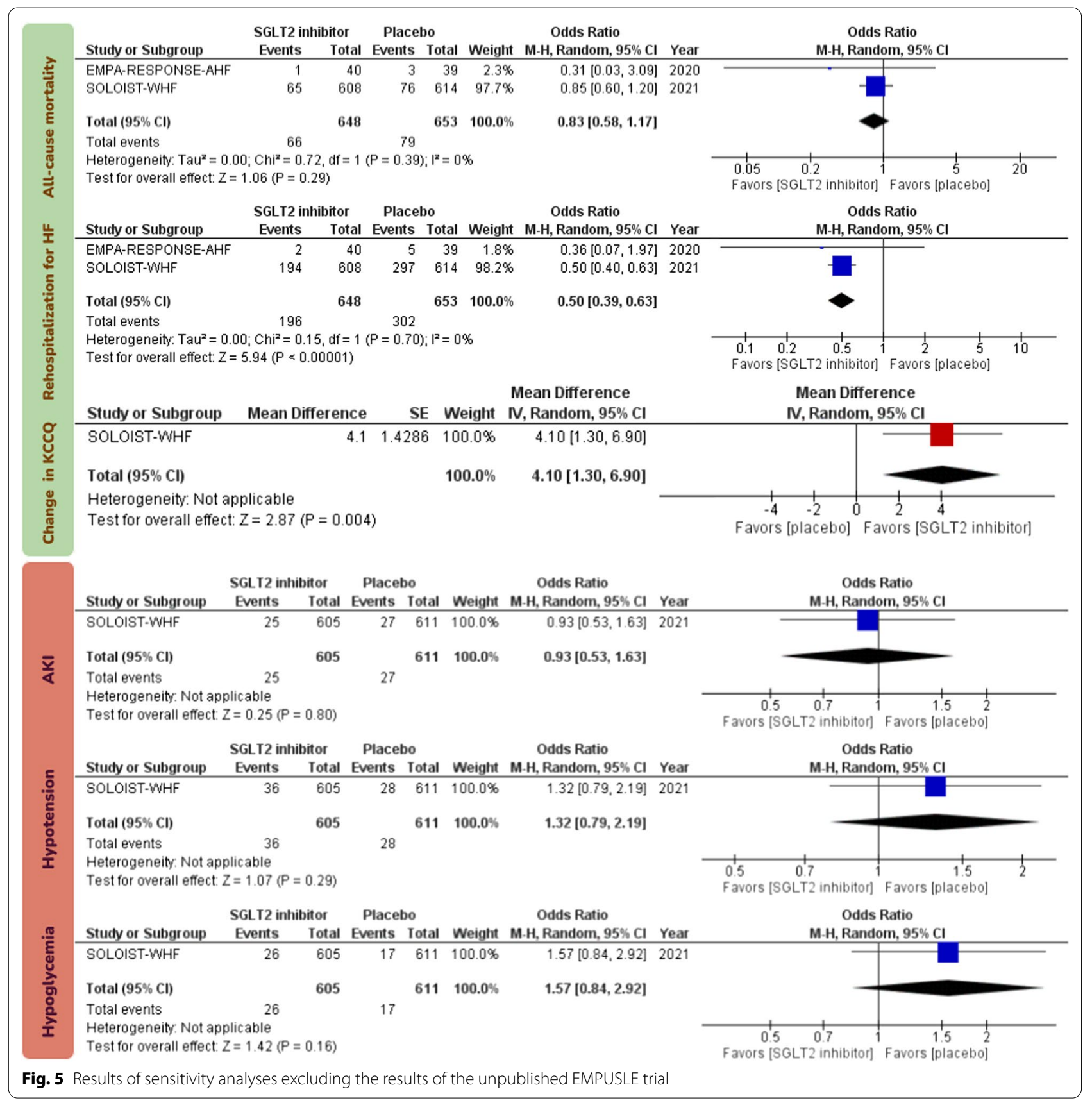

effect, inhibition of the sympathetic nervous system, prevention of ischemia and reperfusion injury, reduction in oxidative stress) [23], initiation of SGLT2 inhibitors in patients with AHF can likely lead to a rapid (as early as day 1 of treatment) and sustained volume unloading and improvement of left ventricular filling pressure and diastolic function [24], which may contribute to the significant reduction in the risk of rehospitalization for HF observed in the present meta-analysis. It is unclear if these benefits in AHF are mediated by a diuretic role for SGLT2 inhibitors; in an analysis of the EMPERORReduced trial, empagliflozin reduced the combined risk of $\mathrm{CV}$ mortality or hospitalization for HF in patients with and without recent volume overload (i.e., 4 weeks before enrollment) with no difference between the groups [25]. Further, changes in body weight correlated poorly with changes in natriuretic peptides or hematocrit, and there were no observed significant changes in serum sodium values [25]. These findings suggest a less dominant diuretic role for SGLT2 inhibitors in their cardioprotective 
mechanisms. Interestingly, in patients with stable chronic $\mathrm{HF}$, the empagliflozin-induced increase in ketone bodies as assessed by beta-hydroxybutyrate causes an attenuation of the beneficial effects of empagliflozin on blood pressure and vascular parameters [26]. While these findings have not yet been confirmed in patients with AHF, such findings may suggest a less pronounced role for afterload reduction as a mechanism driving volume unloading and optimization of left ventricular filling pressure following initiation of SGLT2 inhibitors.

There are several limitations to these meta-analyses that should be noted. First, published summary data rather than individual patient level data were used. Individual patient level data meta-analyses allow for lineby-line patient data collection from the included studies as opposed to only analyzing the measure of effect in published summary data meta-analyses [27]. They also allow for a more consistent identification of the exposure and outcomes across the studies and better adjustment for confounders to minimize heterogeneity [27]. We observe low heterogeneity in all the analyses presented in the current meta-analysis. Second, while the EMPULSE trial used the KCCQ-total symptoms score to measure patient-reported outcomes, the SOLOISTWHF trial used the KCCQ-12, which is the shorter version. However, both scores are scaled similarly $(0-100)$, and KCCQ-12 strongly correlates with the original scale scores with comparable validity, reliability, responsiveness, and prognostic value [13]. Third, the included trials had variable follow-up periods ranging from 60 days as in EMPA-RESPONSE-AHF trial to more than 9 months as in the SOLOIST-WHF trial; while 60 days can be considered a relatively short follow-up period, the main aim of these meta-analyses was to establish the efficacy and safety of SGLT2 inhibitor initiation in the acute setting of HF exacerbation, and for which this follow-up period should be fairly adequate. Fourth, while both EMPARESPONSE-AHF and EMPULSE initiated treatment with SGLT2 prior to discharge in all patients hospitalized for AHF, the SOLOIST-WHF allowed inclusion of patients receiving the first dose of SGLT2 inhibitor up to 3 days after discharge.

\section{Conclusion}

Initiation of SGLT2 inhibitors in patients hospitalized for AHF before discharge or shortly after (within 3 days of discharge) resulted in a reduction in the risk of rehospitalization and improved patient-reported outcomes with no apparent increase in the risk of adverse effects.

\section{Abbreviations}

SGLT2: Sodium-glucose cotransporter 2; GDMT: Guide-directed medical therapy; AHF: Acute heart failure; OR: Odds ratio; Cl: Confidence interval; GRADE:
Grading of Recommendations Assessment, Development and Evaluation; AKI: Acute kidney injury; KCCQ: Kansas City Cardiomyopathy Questionnaire.

\section{Supplementary Information}

The online version contains supplementary material available at https://doi. org/10.1186/s12933-022-01455-2.

Additional file 1: Table S1. Certainty of evidence assessment using GRADE (Grading of Recommendations Assessment, Development and Evaluation) approach.

\section{Acknowledgements}

Not applicable.

\section{Authors' contributions}

HMS conceptualized the idea; conducted study search, selection, data abstracting, and risk of bias assessment; performed statistical analysis; and wrote the initial draft of the manuscript. SJA, MSK, MA, SV, JLM, JPM, SJG, DKM, and RDL participated in writing and revising the manuscript for intellectual content. MF supervised the project; conducted study search, selection, data abstracting, and risk of bias assessment; participated in writing; and revising the manuscript for intellectual content. All authors read and approved the final manuscript.

\section{Funding}

None.

\section{Availability of data and materials}

All the data used to generate this meta-analysis is publicly available.

\section{Declarations}

Ethics approval and consent to participate

N/A to our meta-analysis.

\section{Consent for publication}

All authors have read, approved the submitted version of the manuscript, and provided consent for publication in Cardiovascular Diabetology.

\section{Competing interests}

Al'Aref: Supported by NIH 2R01 HL127661-05, receives royalty fees from Elsevier. Mehta has previously served as consultant to Bayer, Boehringer Ingelheim, AstraZeneca, Medlmmmune and Pfizer; and received grant support from Bayer, Boehringer Ingelheim and AstraZeneca. Current grant support from Department of Veterans Affairs, Veterans Health Administration, Office of Research and Development, Biomedical Laboratory Research and Development (Washington, DC, USA) (Grant No. BX-000282-05). Greene: has received research support from Amgen, AstraZeneca, Bristol Myers Squibb, Cytokinetics, Merck, Novartis, Pfizer, and Sanofi; serves on advisory boards for Amgen, AstraZeneca, Bristol Myers Squibb, Cytokinetics, and Sanofi; and serves as a consultant for Amgen, Bayer, Merck, and Vifor. McGuire: has received personal fees for trial leadership and/or consultancy from Boehringer Ingelheim, Janssen Research and Development LLC, Sanofi US, Merck Sharp and Dohme Corp., Eli Lilly USA, Novo Nordisk, GlaxoSmithKline, AstraZeneca, Lexicon Pharmaceuticals, Eisai, Pfizer, Metavant, Applied Therapeutics, Afimmune and Esperion. Lopes: research grants and personal fees from Bristol-Myers Squibb and Pfizer, personal fees from Boehringer Ingelheim and Bayer AG and grants from Amgen Inc, GlaxoSmithKline, Medtronic PLC, and Sanofi Aventis outside the submitted work. Fudim: Supported by the Mario Family Award, Translating Duke Health Award; Duke Medicine Chair's Award, consulting fees from AstraZeneca, AxonTherapies, CVRx, Daxor, Edwards LifeSciences, Galvani, NXT Biomedical and Respicardia. All other authors report no relevant disclosures.

\section{Author details}

${ }^{1}$ Division of Cardiology, Department of Medicine, University of Arkansas for Medical Sciences, Little Rock, AR, USA. ²Division of Cardiology, Department of Medicine, Duke University, 2301 Erwin Road, Durham, NC, USA. 
${ }^{3}$ Duke Clinical Research Institute, Durham, NC, USA. ${ }^{4}$ Division of Cardiology, Department of Medicine, University Texas Southwestern, and Parkland Health and Hospital System, Dallas, TX, USA.

Received: 17 November 2021 Accepted: 5 January 2022 Published online: 05 February 2022

\section{References}

1. Packer M, Anker SD, Butler J, et al. Cardiovascular and renal outcomes with empagliflozin in heart failure. N Engl J Med. 2020;383(15):1413-24.

2. McMurray JJV, Solomon SD, Inzucchi SE, et al. Dapagliflozin in patients with heart failure and reduced ejection fraction. N Engl J Med. 2019;381(21):1995-2008.

3. Bhatt DL, Szarek M, Steg PG, et al. Sotagliflozin in patients with diabetes and recent worsening heart failure. N Engl J Med. 2020;384(2):117-28.

4. Anker SD, Butler J, Filippatos G, et al. Empagliflozin in heart failure with a preserved ejection fraction. $n$ engl j med. 2021;385(16):1451-61.

5. Salah HM, Al'Aref SJ, Khan MS, et al. Effect of sodium-glucose cotransporter 2 inhibitors on cardiovascular and kidney outcomes-systematic review and meta-analysis of randomized placebo-controlled trials. Am Heart J. 2021;232:10-22.

6. Salah HM, Al'Aref SJ, Khan MS, et al. Effects of sodium-glucose cotransporter 1 and 2 inhibitors on cardiovascular and kidney outcomes in type 2 diabetes: a meta-analysis update. Am Heart J. 2021;233:86-91.

7. Butler J, Packer M, Filippatos G, et al. Effect of empagliflozin in patients with heart failure across the spectrum of left ventricular ejection fraction. Eur Heart J. 2021. https://doi.org/10.1093/eurheartj/ehab798.

8. Zannad F, Ferreira JP, Pocock SJ, et al. SGLT2 inhibitors in patients with heart failure with reduced ejection fraction: a meta-analysis of the EMPEROR-Reduced and DAPA-HF trials. Lancet. 2020;396(10254):819-29.

9. Maddox TM, Januzzi JL, Allen LA, et al. 2021 Update to the 2017 ACC expert consensus decision pathway for optimization of heart failure treatment: answers to 10 pivotal issues about heart failure with reduced ejection fraction. J Am Coll Cardiol. 2021;77(6):772-810.

10. McDonagh TA, Metra M, Adamo M, et al. 2021 ESC Guidelines for the diagnosis and treatment of acute and chronic heart failure: Developed by the Task Force for the diagnosis and treatment of acute and chronic heart failure of the European Society of Cardiology (ESC) with the special contribution of the Heart Failure Association (HFA) of the ESC. Eur Heart J. 2021:42(36):3599-726.

11. Rao VN, Murray E, Butler J, et al. In-hospital initiation of sodium-glucose cotransporter-2 inhibitors for heart failure with reduced ejection fraction. J Am Coll Cardiol. 2021;78(20):2004-12.

12. Green CP, Porter CB, Bresnahan DR, Spertus JA. Development and evaluation of the Kansas City Cardiomyopathy Questionnaire: a new health status measure for heart failure. J Am Coll Cardiol. 2000;35(5):1245-55.

13. Spertus JA, Jones PG. Development and validation of a short version of the kansas city cardiomyopathy questionnaire. Circ Cardiovasc Qual Outcomes. 2015;8(5):469-76.

14. Butler J, Anker SD, Filippatos G, et al. Empagliflozin and healthrelated quality of life outcomes in patients with heart failure with reduced ejection fraction: the EMPEROR-Reduced trial. Eur Heart J. 2021;42(13):1203-12.

15. Higgins JPT, Altman DG, Gøtzsche PC, et al. The Cochrane Collaboration's tool for assessing risk of bias in randomised trials. BMJ. 2011;343:d5928.

16. Damman K, Beusekamp JC, Boorsma EM, et al. Randomized, doubleblind, placebo-controlled, multicentre pilot study on the effects of empagliflozin on clinical outcomes in patients with acute decompensated heart failure (EMPA-RESPONSE-AHF). Eur J Heart Fail. 2020;22(4):713-22.

17. Debray TPA, Moons KGM, Riley RD. Detecting small-study effects and funnel plot asymmetry in meta-analysis of survival data: a comparison of new and existing tests. Res Synth Methods. 2018;9(1):41-50.

18. Tromp J, Ponikowski P, Salsali A, et al. Sodium-glucose co-transporter 2 inhibition in patients hospitalized for acute decompensated heart failure: rationale for and design of the EMPULSE trial. Eur J Heart Fail. 2021;23(5):826-34.

19. Carnicelli AP, Lippmann SJ, Greene SJ, et al. Sacubitril/Valsartan initiation and postdischarge adherence among patients hospitalized for heart failure. J Cardiac Fail. 2021;27(8):826-36.
20. Curtis LH, Mi X, Qualls LG, et al. Transitional adherence and persistence in the use of aldosterone antagonist therapy in patients with heart failure. Am Heart J. 2013;165(6):979-986.e971.

21. Salah HM, Minhas AMK, Khan MS, et al. Trends in hospitalizations for heart failure, acute myocardial infarction, and stroke in the United States from 2004 to 2018. Am Heart J. 2022;243:103-9.

22. Salah HM, Minhas AMK, Khan MS, et al. Causes of hospitalization in the USA between 2005 and 2018. Eur Heart J Open. 2021;1(1).

23. Lopaschuk GD, Verma S. Mechanisms of cardiovascular benefits of sodium glucose co-transporter 2 (SGLT2) inhibitors. JACC Basic Transl Sci. 2020;5(6):632-44.

24. Rau M, Thiele K, Hartmann NK, et al. Empagliflozin does not change cardiac index nor systemic vascular resistance but rapidly improves left ventricular filling pressure in patients with type 2 diabetes: a randomized controlled study. Cardiovasc Diabetol. 2021;20(1):6.

25. Packer M, Anker SD, Butler J, et al. Empagliflozin in patients with heart failure, reduced ejection fraction, and volume overload. J Am Coll Cardiol. 2021;77(11):1381-92

26. Pietschner R, Kolwelter J, Bosch A, et al. Effect of empagliflozin on ketone bodies in patients with stable chronic heart failure. Cardiovasc Diabetol. 2021;20(1):219

27. Thomas D, Radji S, Benedetti A. Systematic review of methods for individual patient data meta- analysis with binary outcomes. BMC Med Res Methodol. 2014;14:79-79.

\section{Publisher's Note}

Springer Nature remains neutral with regard to jurisdictional claims in published maps and institutional affiliations.

Ready to submit your research? Choose BMC and benefit from:

- fast, convenient online submission

- thorough peer review by experienced researchers in your field

- rapid publication on acceptance

- support for research data, including large and complex data types

- gold Open Access which fosters wider collaboration and increased citations

- maximum visibility for your research: over 100M website views per year

At BMC, research is always in progress.

Learn more biomedcentral.com/submissions 